\title{
Motion control applications: observer based DC motor parameters estimation for novices
}

\author{
Branesh M. Pillai, Jackrit Suthakorn \\ Department of Biomedical Engineering, Faculty of Engineering, Mahidol University, Thailand
}

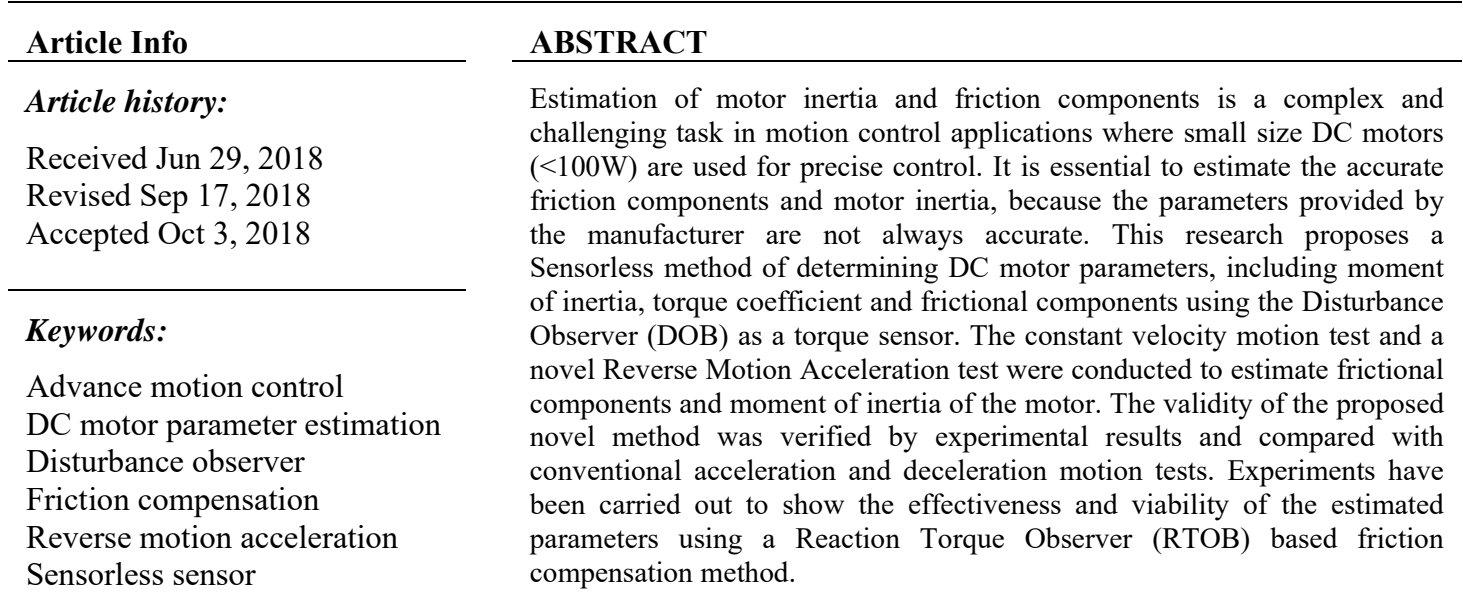

Copyright (C) 2019 Institute of Advanced Engineering and Science. All rights reserved.

\section{Corresponding Author:}

Jackrit Suthakorn,

Center for Biomedical and Robotics Technology (BART LAB),

Department of Biomedical Engineering, Faculty of Engineering, Mahidol University, 999, Phuttamonthon Sai 4, Salaya, Nakorn Pathom, 73170, Thailand.

Email: jackrit.sut@mahidol.ac.th

\section{INTRODUCTION}

Motion control techniques have been significantly developed in recent decades. The first IEEE International Workshop on Advanced Motion Control, held in 1990 emphasized the importance of physical interpretation of motion control. Motion control systems play a vital role in many industrial automation applications, such as position control, velocity control, acceleration control, force control etc. The performance of industrial robotic application systems is mainly based on position and force control [1]. DC servomotors are often used to achieve precise position and torque control. Moreover, in medical robotics applications, DC servomotors are widely used due to its simple structure and outstanding control performance at low cost [2].

DC servomotors used for control applications should incorporate accurate control methods to obtain the desired responses. Controller parameters in such applications have to be tuned properly to obtain the desired response of the system [3]. Tuning of controller parameters depends on the physical parameters of the systems. Therefore, the identification of accurate physical parameters of systems is important. Armature resistance $R_{a}$, armature inductance $L_{a}$ and back emf constant $K_{e}$ are considered to be fixed for a given DC motor. Once a DC motor is in operation, the torque constant $K_{t}$ may change due to magnetic effects. Motor inertia $J$ may change due to the addition or removal of loads to the rotary shaft [4].

DC motor friction compensation was a complex task and has been tried by many researchers. However, no one has introduced an effective strategy for friction compensation of small size DC motors [5][7]. There is no research available considering the four parameters (friction components $\left(T_{f}\right.$ and $\left.B \dot{\theta}\right)$, 
mechanical parameter $J$ and electrical parameter $K_{t}$ ) in a single experiment. In order to achieve accurate force control based friction compensation, it is essential to identify the system parameters accurately and deal with the non-linear friction components [8]. In this research, the authors propose a novel RTOB model based friction compensation method using a PID controller. If the friction components and mechanical parameters of the system are accurate, then the proposed friction compensation method will give the desired system characteristics.

Frictional components also may vary with wear and tear effects [9], [10]. Usually motor manufacturers may supply the parameters $K_{t}$ and $J$. However, for smaller size DC motors $(10-100 \mathrm{~W})$, manufacturers' given values for commercially available motors may not always be accurate. For precise control applications, the accuracy of the motor parameters is very important [11]-[13]. Manufacturers do not normally supply friction related parameters. The varying parametric value of DC motors can also be attributed to the load connected with the motor [14]. The friction components present in a DC servo motor are static friction, coulomb friction, viscous friction and Stribeck friction.

Generally, Stribeck friction is generated using fluid lubricants and the effect of this friction is ignored in this research. Coulomb friction is independent of velocity and is assumed negligible for small size DC motors. The static friction $T_{f}$ is the force required in order to start the motion from a stand still. This friction is also called as the breakaway friction. When the motor starts to rotate, viscous friction appears and it increases with the increase of velocity. The estimation of accurate friction components $\left(T_{f}\right.$ and $\left.B \dot{\theta}\right)$ and the mechanical parameters $\left(K_{t}\right.$ and $\left.J\right)$ lead to the desired system response [15]. In this paper, the estimation of static friction, viscous friction, torque constant and motor inertia are discussed in detail.

Several methods of identification for DC motor parameters have been proposed using various techniques. Many researchers have proposed methods of finding mechanical parameters of DC motors [1621]. For example, [16] the general system parameters identification is considered. The distribution-based approach [17] is used to identify parameters from discrete time data. The fuzzy PID [18] is used to estimate the loaded torque; the least-squares algorithm is implemented [19]-[21] to estimate system parameters. However, none of them can be effectively used for small size DC motors. In [22], the importance of estimation of parameters was emphasized, but there were no methods for estimating the motor inertia and the frictional components. Although there are researches to estimate the viscous friction of DC motors used in precise control applications such as position control, the torque coefficient and motor inertia were not taken into consideration [23]-[26]. In [27], load model parameters were obtained using an evolutionary algorithm but the friction coefficient of the motor was not considered.

Tuning the controller parameters for the desired system response can be achieved only with accurately estimated physical parameters of the system. In motion control applications, the real time desired system response is not achievable if controller tuning is done based only on the nominal motor parameters without considering the physical parameter variations [28]. The algebraic identification method [29], [30] are to estimate the parameters for a continuous time system. The recursive least square method [31] and the inverse theory with conjugate gradient method [32] are used to determine system parameters.

In this research, the torque coefficient $K_{t}$ was estimated using the conventional DC motor rotor stall test. The friction components were identified by conducting the constant velocity motion test [33]. Here, the disturbance observer (DOB) is used as a torque sensor. DOB identifies the total mechanical load and the effect of system parameter change that is considered as the total disturbance of the motor [34], [35]. In order to estimate the motor inertia, the authors propose a RTOB based novel Reverse Motion Acceleration test. RTOB subtracts the identified parameters from the disturbance torque and hence outputs the reaction torque applied to the system [36]-[39].

The estimated motor inertia using Reverse Motion Acceleration test was compared with conventional acceleration and deceleration tests results. The results of these three tests were analyzed and compared in section 3 . The estimated parameters were validated by conducting a force control based friction compensation test. Experiments where carried out to show the importance and validity of the all estimated parameters using Reaction Torque Observer (RTOB) based friction compensation technique as explained in section 4 . The proposed inertia values were compared with the conventional test results using the same friction compensator.

Int J Pow Elec \& Dri Syst, Vol. 10, No. 1, March 2019 : $195-210$ 


\section{MODELING}

\subsection{DC motor modeling}

Using Kirchhoff's voltage law in circuit as shown in Figure 1.

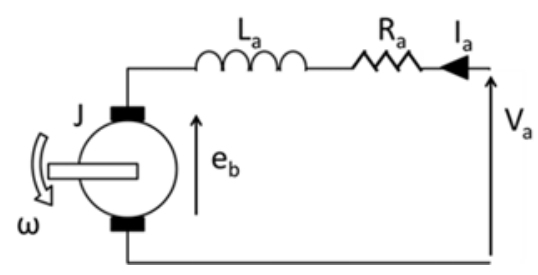

Figure 1. Electrical model of a DC motor

And,

$$
\begin{gathered}
e_{b}=K_{e} \dot{\theta} \\
T_{m}=K_{t} I_{a}
\end{gathered}
$$

Motor torque is expressed as,

$$
T_{m}=J \frac{d \dot{\theta}}{d t}+T_{f}+B \dot{\theta}+T_{l}
$$

Where, $R_{a}$ - Armature resistance; La - Armature inductance; $I_{a}$ - Armature current; $K_{t}$ - Torque coefficient; $J$ Moment of inertia of motor; $K_{e}$ - Back emf constant; $V_{a}$ - Armature voltage; $e_{b}$ - Back emf; $\dot{\theta}$ - Angular speed; $\mathrm{T}_{\mathrm{m}}$ - Motor torque; $T_{i^{-}}$Load torque ; Tf-Static friction torque; $B$-Viscous friction coefficient. $T_{L}$ consists of external applied torque and all the disturbance effects of the system as shown in Figure 2(a). (4) can be rewritten as follows.

$$
\begin{aligned}
& J \ddot{\theta}=T_{m}-T_{L} \\
& J \ddot{\theta}=K_{t} I_{a}-T_{L}
\end{aligned}
$$

Where $T_{L}$ consists of inertia torque, external torque and torque due to Coulomb and viscous friction.

$$
T_{L}=T_{l}+T_{f}+B \dot{\theta}
$$

The input to the motor is the reference current $I a$ and is controlled according to the PWM voltage pulses [40], [41]. With the $T_{L}$ motor torque cannot be directly controlled using Ia. Therefore, for correct functionality, $T_{L}$ must be compensated as shown in Figure 2(b). $T_{L}$ is referred to as 'Disturbance Torque' as this torque disturbs the output torque. To measure this disturbance torque and compensate for it, the 'Disturbance Observer' is introduced [42] as shown in Figure 2(c). 


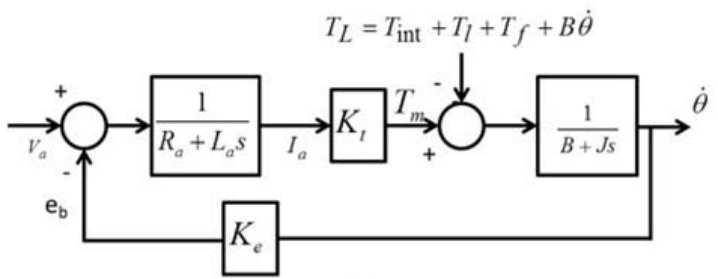

(a)

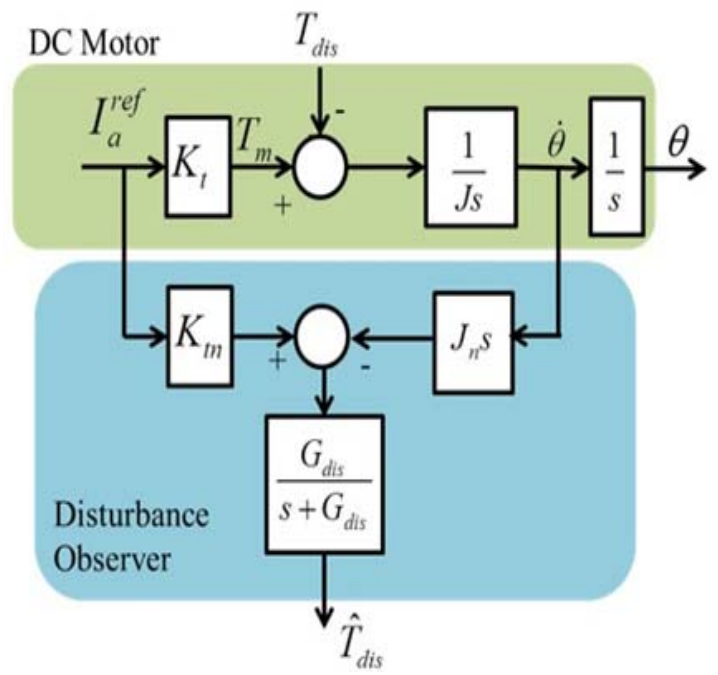

(c)

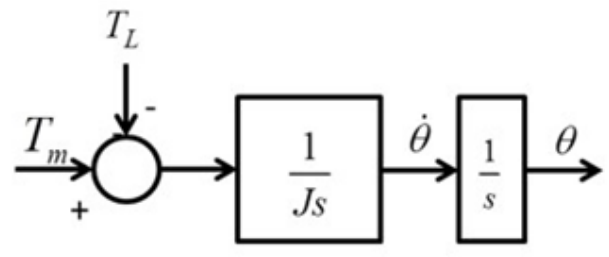

(b)

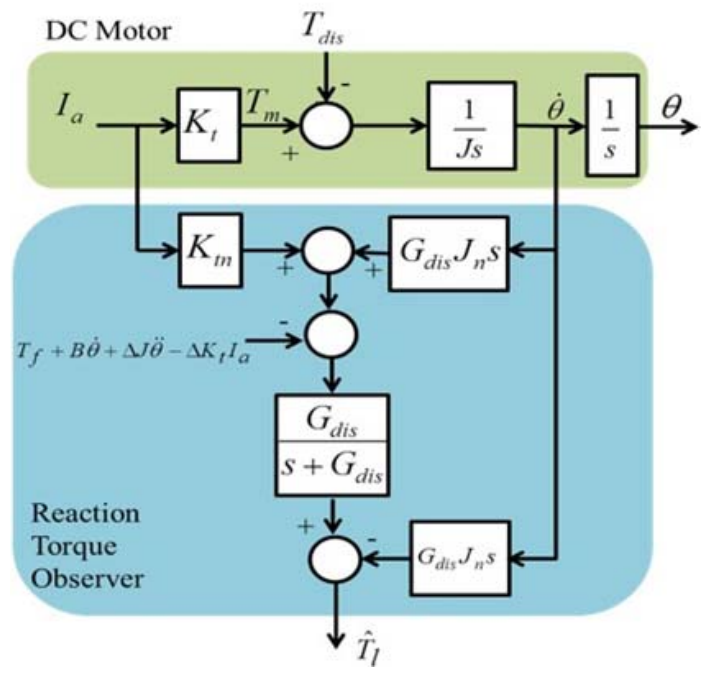

(d)

Figure 2. (a) Block diagram of DC motor (b) Block diagram of servomotor (c) Disturbance observer control block (d) Reaction torque observer control block

\subsection{Disturbance observer modeling}

In (6) has two parameters, named motor inertia and torque constant. These two parameters may be changed due to several properties. Inertia may be changed due to the mechanical configuration of the motion system. The torque coefficient will vary according to the rotor position of the electric motor due to irregular distribution of magnetic flux on the surface of the rotor [43], [44].

$$
\begin{aligned}
& J=J_{n}+\Delta J \\
& K_{t}=K_{t n}+\Delta K_{t}
\end{aligned}
$$

$J_{n}$ - Nominal motor inertia; $\Delta J$-Inertia variation; $K_{t n}$ - Nominal torque coefficient; $\Delta K_{t}$-Variation of torque coefficient. From (6)-(9) it can be determined that,

$$
T_{\text {dis }}=K_{t n} I_{a}-J_{n} \ddot{\theta}
$$

In (10), the unknown value of $T_{\text {dis }}$ is calculated using the known values at right hand side. From (11), $T_{\text {dis }}$ is calculated as follows.

$$
T_{d i s}=T_{l}+T_{f}+B \dot{\theta}+\Delta J \ddot{\theta}-\Delta K_{t} I_{a}
$$


Normally, disturbance torque consists of all internal torques, external torques, friction torques and torques due to parameter variations, which must have compensated for to obtain the accurate output torque. The estimated disturbance torque $\hat{T}_{d i s}$ is obtained from the velocity response $\dot{\theta}$ and the torque current $I_{a}$. It is estimated through a first-order low-pass filter as shown in Figure 2(c) where $G_{\text {dis }}$ denotes the cut-off frequency of the low-pass filter. The purpose of the low-pass filter is to filter out noise arising from differentiation [45], [46].

\subsection{Reaction torque observer modeling}

The disturbance observer is used not only for disturbance compensation but also for reaction torque estimation. The disturbance observer is able to estimate the reaction torque without using a torque sensor by identifying the internal disturbance of the system [47]. When the motor is running with a load, the load torque exerted on the motor due to the load is obtained from equation (12). As shown in Figure 2(d), all the disturbance components are removed at the reaction torque observer; hence, the RTOB output is the estimated load torque $\widehat{T}_{i}$.

$$
T_{l}=T_{\text {dis }}-\left(T_{f}+B \dot{\theta}+\Delta J \ddot{\theta}-\Delta K_{t} I_{a}\right)
$$

\section{DC MOTOR PARAMETER ESTIMATION METHODS}

\subsection{Experimental Setup}

In the experiment, as shown in Figure 3, the system composed of 1-DOF main motor, manufactured by Maxon RE-max 29 and the motor specifications are listed in Table 1 and a motor driver SE-HB-40-1 with driver IC (IRF $4905 \mathrm{~S} / \mathrm{L}$ ) along with a current sensor, which can carry a current of up to 40A peak load. The current sensor installed in the system is to estimate the actual current of the main motor. The motor driver is operated by the PWM signals generated by the processor. An encoder coupled with the main motor does position sensing.

Table 1. DC Motor specifications

\begin{tabular}{ccc}
\hline Parameter & Value & Units \\
\hline Rated output & 67.2 & $\mathrm{~W}$ \\
Rated/max torque & $21.5 / 146$ & $\mathrm{mNm}$ \\
Encoder resolution & 512 & Pulse/rev \\
\hline
\end{tabular}

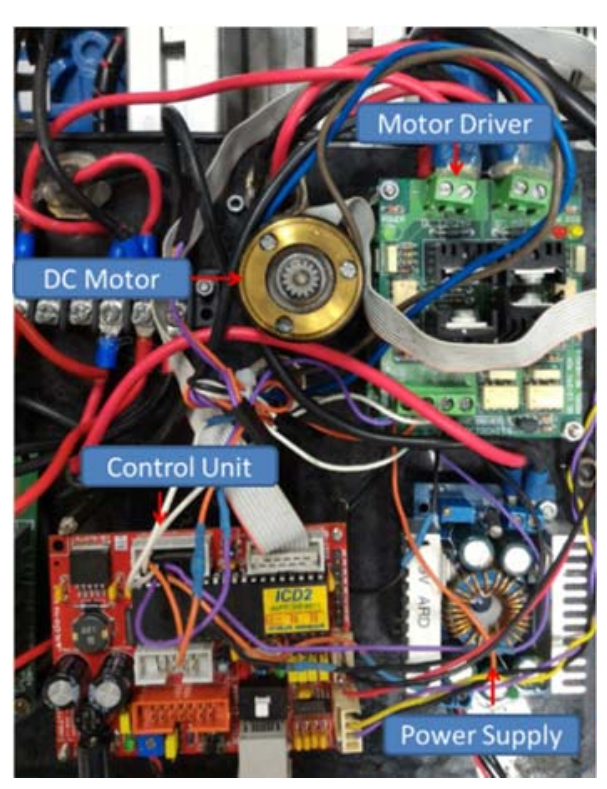

Figure 2. One DOF rotational manipulator 


\subsection{Estimation of Torque Coefficient $\left(K_{t}\right)$}

It is important to identify the exact $K_{t}$ of DC motor, since the given value from manufacturers may not be an exact representation of $K_{t}$ for the loaded DC motor. The change of the torque coefficient is also considered as a disturbance to the motor. The input power $P$ of the DC motor can expressed in terms of torque $\tau$ and angular velocity $\dot{\theta}$.

$$
P=\tau \dot{\theta}
$$

The power $P$ also can be represented using armature voltage $V_{a}$ and armature current $I_{a}$.

$$
\begin{aligned}
& P=V_{a} I_{a} \\
& \tau=K_{t} I_{a}
\end{aligned}
$$

From (14) and (15) it can be shown as

$$
V_{a}=K_{t} \dot{\theta}
$$

Hence, the angular velocity is directly proportional to the armature voltage, and the armature current is an independent variable in this relationship. When the DC motor is running under no load conditions, the $K_{t}$ value does not vary. However, $K_{t}$ may vary when the motor is loaded. The change of $K_{t}$ of the loaded motor was determined using the conventional rotor stall test. Figure 4 shows the setup used for a rotor stall test [48]. This experiment was conducted to measure motor torques against a range of armature currents. In this test, torque coefficient was obtained from the slope of the graph of Figure 8, by plotting the variation of torque against the armature current. The torque coefficient $K_{t}$ found using (15) from Figure 5(a) is 0.256 $\mathrm{Nm} / \mathrm{A}$.

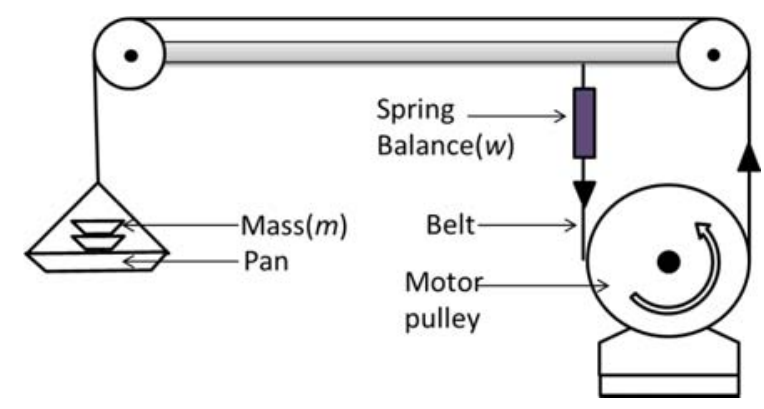

Figure 3. Rotor stall test

\subsection{Estimation of Friction Components}

The authors propose use of Disturbance Observer (DOB) [1], [40] in a closed loop control system, to estimate the disturbances torque to find the friction components. The disturbance observer identifies the total mechanical load torque and the effects of system parameters as represented in equation (11). The friction components were estimated by conducting a constant velocity motion test [48], [40], when the motor is running at a constant velocity. The acceleration of the motor is zero and hence there is no effect on the motor inertia $J$ [48]. The torque coefficient was $0.0256 \mathrm{Nm} / \mathrm{A}$ form the previously discussed rotor stall test. The test was conducted with no-load conditions and therefore the external torque is zero. The DOB output given as,

$$
T_{\text {dis }}=T_{f}+B \dot{\theta}
$$


A PID based DOB incorporating a tuned velocity controller was used to obtain a better velocity response with this constant velocity test [47]. The corresponding experimental parameter values were shown in Table 2. The test was conducted with different constant velocities ranging from $+5000 \mathrm{rpm}$ to $-5000 \mathrm{rpm}$. Figure 5(b) and (c) show the velocity response and the observer output (disturbance torque). In this test, as shown in equation (18), the DOB output consists of friction components and the change of inertia effect of the system $\Delta J \ddot{\theta}$. This $\Delta J \ddot{\theta}$ effect exists only within the acceleration period.

$$
T_{d i s}=T_{f}+B \dot{\theta}+\Delta J \ddot{\theta}
$$

For the estimation of friction components, only the linear velocity region was considered, and acceleration is zero during the period.

Table 2. Experimental parameters

\begin{tabular}{ccc}
\hline Parameter & Value & Units \\
\hline Motor Inertia $\left(\mathrm{J}_{\mathrm{n}}\right)$ & 13.5 & $\mathrm{~g} \mathrm{~cm}^{2}$ \\
Torque Coefficient $\left(\mathrm{K}_{\mathrm{t}}\right)$ & 0.256 & $\mathrm{Nm} / \mathrm{A}$ \\
$\mathrm{K}_{\mathrm{P}}$ Constant: PID & 0.01 & \\
$\mathrm{~K}_{\mathrm{I}}$ Constant: PID & $10^{-4}$ & \\
$\mathrm{~K}_{\mathrm{D}}$ Constant: PID & 0.006 & \\
Cut-off frequency of low pass & 0.003 & $\mathrm{~Hz}$ \\
filter $\left(\mathrm{G}_{\mathrm{dis}}\right)$ & & \\
\hline
\end{tabular}

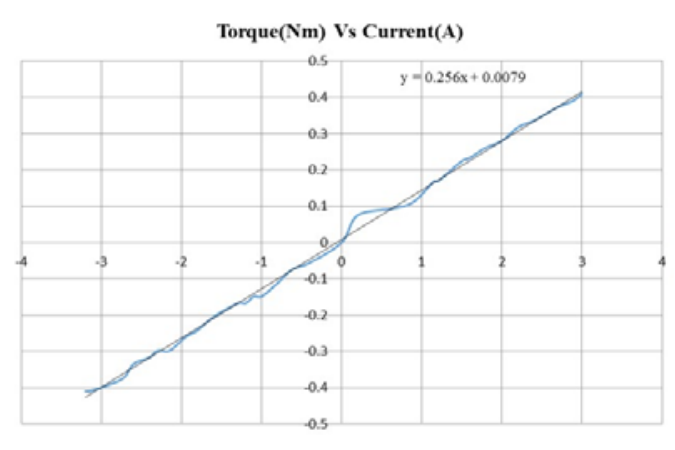

(a)

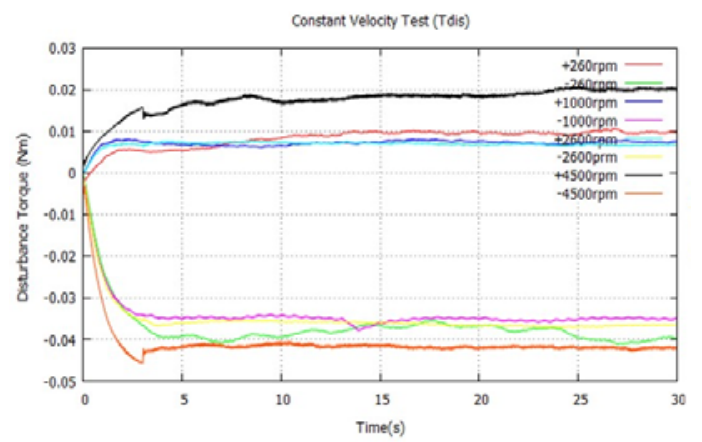

(c)

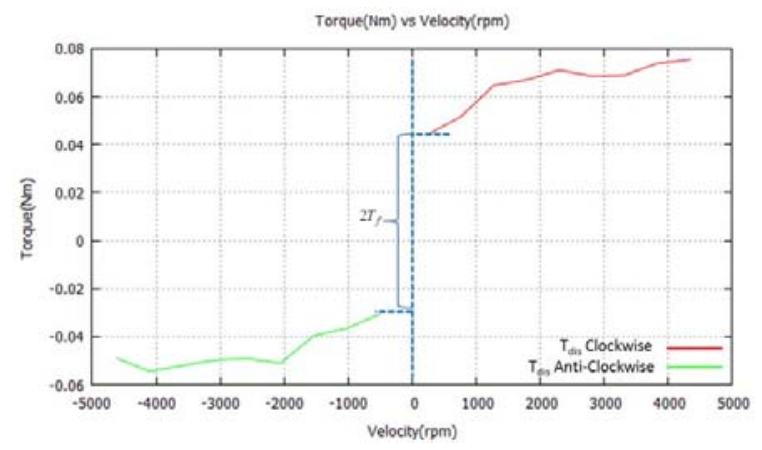

(b)

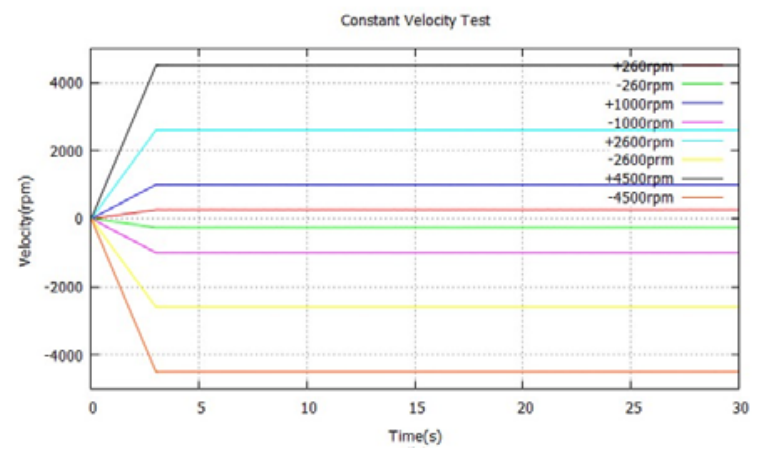

(d)

Figure 5. (a) Torque response against current (b) Velocity response of the constant velocity test (c) Disturbance observer output for different velocities (d) Measured friction torque

Observer output is averaged from 10 seconds to 30 seconds from Figure 5(b). Averaged observer output against the corresponding velocity is redrawn in Figure 5(d), for clockwise and anti clockwise

Motion control applications: observer based DC motor parameters estimation for... (Branesh M. Pillai) 
directions. The anti clockwise direction shows a higher friction for the given DC motor. Static friction $T_{f}$ is averaged for both directions and can be calculated as shown in Figure 5(d). However, $T_{f}$ for each direction is also calculable. The calculated average static friction value $T_{f}$ is $0.0375 \mathrm{Nm}$. The viscous friction coefficient $B$ was mathematically identified by using a standard curve fitting model from Figure 5(b), and estimated using both the standard linear regression method and the method of evaluation [49], and expressed in (19).

$$
B \dot{\theta}=0.0002573 \dot{\theta}
$$

The validity of these estimated friction components is proven in the friction compensation section $4(B)$.

\subsection{Estimation of motor inertia $(\mathbf{J})$}

In (11), the inertia of the motor $J$ subjected to variations is described. This variation is also considered as a disturbance of the DC motor. Identification and compensation of the change of inertia improve the DC motor robustness in operation. However, both identifying and compensating the inertia variations are important tasks. There are no straightforward methods for this [16-21]. To overcome this barrier, in this research, the authors propose a RTOB based inertia calculation and compensation technique. Estimation of motor inertia estimated in three different ways: conventional acceleration, deceleration motion test and novel Reverse Motion Acceleration test.

\subsubsection{Acceleration motion test}

In this test, the DC motor is attached with a planetary gearhead of ratio 246:1 brought to its rated speed from initial zero speed. As shown in Figure 6(a), the acceleration of the motor was calculated by dividing the rated speed to the time taken to reach its rated speed.

$$
\text { Motor Inertia }(J)=\frac{\text { Acceleration Torque }}{\text { Acceleration }}\left(\mathrm{kg}-\mathrm{m}^{2}\right)
$$

Direct calculation of the acceleration torque is not possible with the conventional method. In this experiment, the authors used RTOB as the torque sensor. The acceleration torque is the output of the torque sensor. The calculated motor inertia value from this test using equation (20) is $16.7 \mathrm{~g} \mathrm{~cm}^{2}$.

\subsubsection{Deceleration Motion Test}

The power supply to the motor is disconnected when the motor is running at its rated speed. The motor speed then reduces to zero from its steady speed as shown in Figure 6(b), the dynamic torque equation for this test becomes (21).

$$
J \ddot{\theta}+T_{f}+B \dot{\theta}=0
$$

The time domain solution obtained for equation (21) is expressed as below with a calculable constant $A$.

$$
t=-\frac{T_{f}}{B}+A e^{-(B / J) \dot{\theta}}
$$

The calculated motor inertia in the deceleration motion test is $14.2 \mathrm{~g} \mathrm{~cm}^{2}$.

\subsubsection{Reverse motion acceleration test}

This is a novel method introduced by the authors to estimate the motor inertia. Here, RTOB is used as a torque sensor. The calculated values for motor parameters values $\left(K_{t}, T_{f}\right.$ and $\left.B\right)$ were used for this test. A DOB based robust velocity controller was used to achieve accurate velocity responses. The test was conducted by reversing the motor direction suddenly whereas it was running at steady state speed. The controller governs the immediate change of the direction as shown in Figure 6(c), the motor acceleration to the opposite direction starts at $t_{1}$ and ends at $t_{2}$. At $t_{2}$, the motor approaches a steady state speed in the opposite direction. This direction variation results in a variation of torque, and from these variations the motor inertia is directly estimated.

Int J Pow Elec \& Dri Syst, Vol. 10, No. 1, March 2019 : 195 - 210 
The RTOB output of Reverse motion acceleration test $\hat{T}_{\text {dis }}$ consists of only the change of motor inertia. The known disturbance components were eliminated in the inner loop of the RTOB as explained in Figure 2(d).

$$
\hat{T}_{d i s}=\Delta J \ddot{\theta}
$$

From (8), $\hat{T}_{\text {dis }}$ in (23) is expressed as

$$
\hat{T}_{d i s}=\left(J-J_{n}\right) \ddot{\theta}
$$

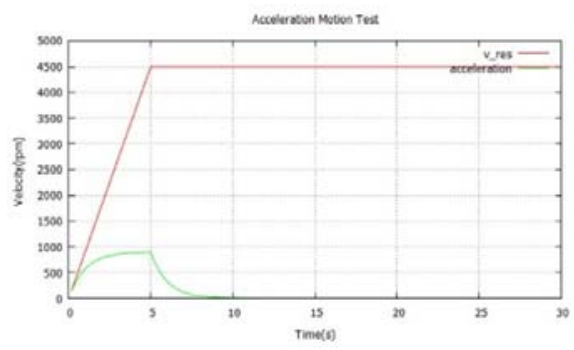

(a)

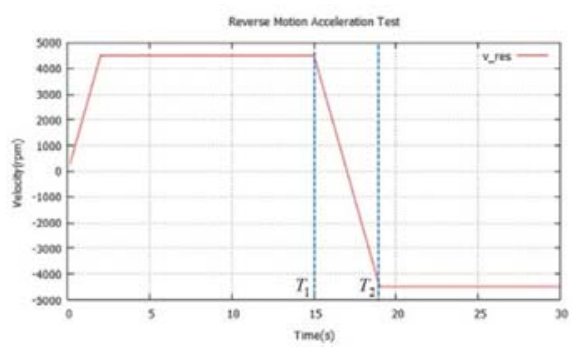

(c)

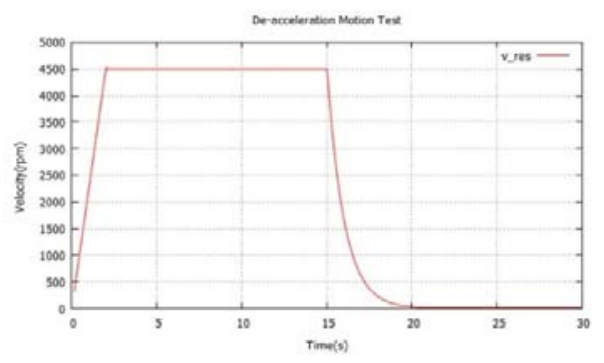

(b)

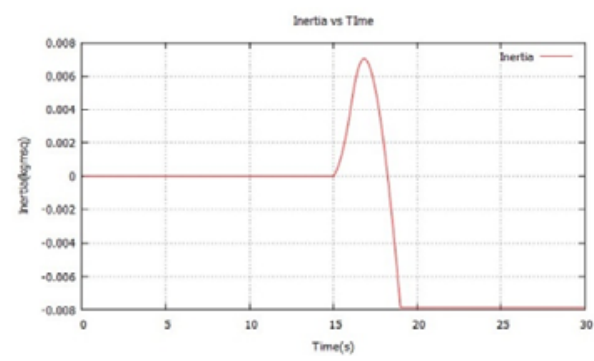

(d)

Figure 4. (a) Velocity \& acceleration response of acceleration motion test (b) Velocity response of deceleration motion test (c) Velocity response of reverse motion acceleration test (d) Inertia response of reverse motion acceleration test

By integrating (24) for the time interval $t_{1}$ to $t_{2}$, the above expression can be rewritten as follows:

$$
\int_{t_{1}}^{t_{2}} \hat{T}_{d i s} d t=\left(J-J_{n}\right)\left[\dot{\theta}\left(t_{2}\right)-\dot{\theta}\left(t_{1}\right)\right]
$$

Motor inertia $J$ can be calculated from the right hand side known parameters of (26).

$$
J=J_{n}+\frac{1}{\left[\dot{\theta}\left(t_{2}\right)-\dot{\theta}\left(t_{1}\right)\right]} \int_{t_{1}}^{t_{2}} \hat{T}_{d i s} d t
$$

From (26) and Figure 6(d) the calculated motor inertia is $19.1 \mathrm{~g} \mathrm{~cm}^{2}$.

\section{EXPERIMENTS AND RESULTS}

A novel approach, RTOB based friction compensation model is introduced in this research to evaluate the estimated frictional and inertail values. The block diagram of the proposed system is shown in Figure 7. In order to achieve the accurate inertial value, this research derived the innovative (26). The

Motion control applications: observer based DC motor parameters estimation for... (Branesh M. Pillai) 
significance of this equation is that it compensates for (24) value between that of the manufacturer and actual inertia.

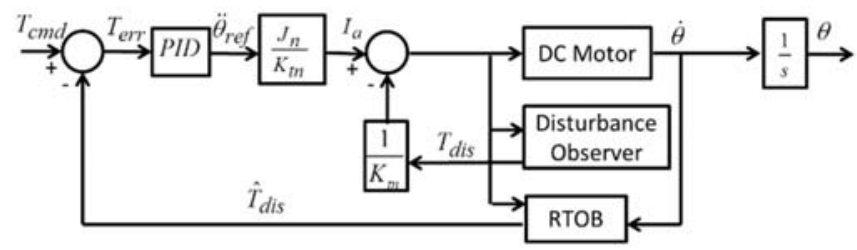

Figure 5. RTOB based friction compensation model

\subsection{Stability Analysis}

Friction sometimes causes reduced tracking performance in control systems when it is uncompensated. This section analyzes the stability of the system when the friction is compensated. The simplified transfer function (27) between the input $T_{\text {dis }}$ and output $\dot{\theta}$ is derived from Figure 7 . The experimental values used for the MATLAB simulations are listed in Table 3 . The stability of the system is analyzed using root locus plot for (27) shown in Figure 8. The transfer function gain $K$ is changed from 1 to 10000 , resulting in stable characteristics of the system. This illustrates that the friction compensated system is stable. The effects of the parameter change were analyzed for the friction compensated system to measure the stability [50].

$$
\frac{\dot{\theta}}{T_{d i s}}=\frac{\left(T_{f} G_{d i s}-Y K_{t n}\left(s+G_{d i s}\right)\right)\left(s K_{p}+s^{2} K_{d}+K_{I}\right) K_{t}-s K_{t n}\left(s+G_{d i s}\right)}{\left(T_{f}+B\right)\left(J s^{2}\left(s+G_{d i s}\right) K_{t n}-K_{t} B G_{d i s}\left(s K_{p}+s^{2} K_{d}+K_{I}\right)\right)}
$$

Where, $Y$ is the current sensor output gain.

The system parameters $J, B$ and $T_{f}$ were assumed to be changed by $\Delta$ with respect to their nominal values. The subscript $n$ is used to denote the nominal values.

$$
\begin{aligned}
& J=J_{n}+\Delta J \\
& B=B_{n}+\Delta B \\
& T_{f}=T_{f n}+\Delta T_{f}
\end{aligned}
$$

The system frequency response is analyzed using bode plot tool in MATLAB to identify the effect of parameter change. Figure 8 (a) \& (b) shows the root locus plot and bode plot of inertia change respectively and arrows indicate that the responses vary with $\Delta J$. When $\Delta J$ element increases, the conjugate roots move along imaginary axes, but the system remains stable. The effect of $\Delta J$ is negligible for low frequencies and is significant for higher frequencies (practical frequencies) [33]. Therefore, the estimation of an accurate $J$ is important for a stable system.

In Figure 8 (c) \& (d), there is no substantial effect on stability and frequency responses when changing $\Delta B$ element. It is evident that the effect is significant only for low frequencies. Figure 8 (e) and (f) show the responses corresponding to $\Delta T_{f}$ element. The analysis of the effect of parameter change validates that selecting the correct $J$ and $T_{f}$ values are vital for a stable system, and hence the friction compensated system's stability depends on them.

Int J Pow Elec \& Dri Syst, Vol. 10, No. 1, March 2019 : 195 - 210 


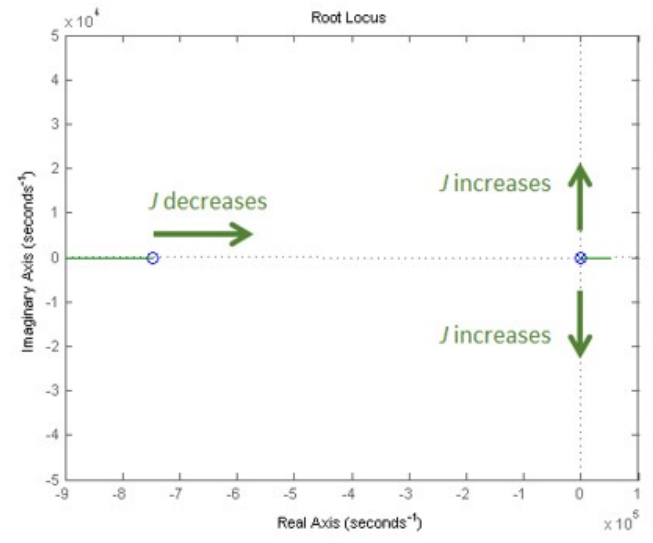

(a)

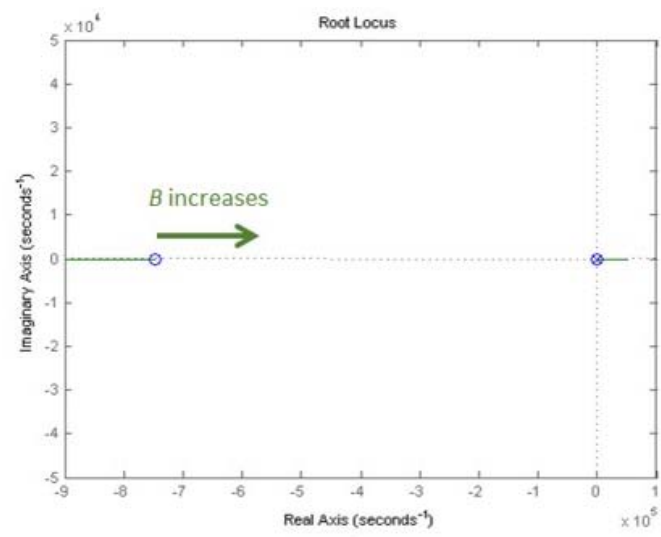

(c)

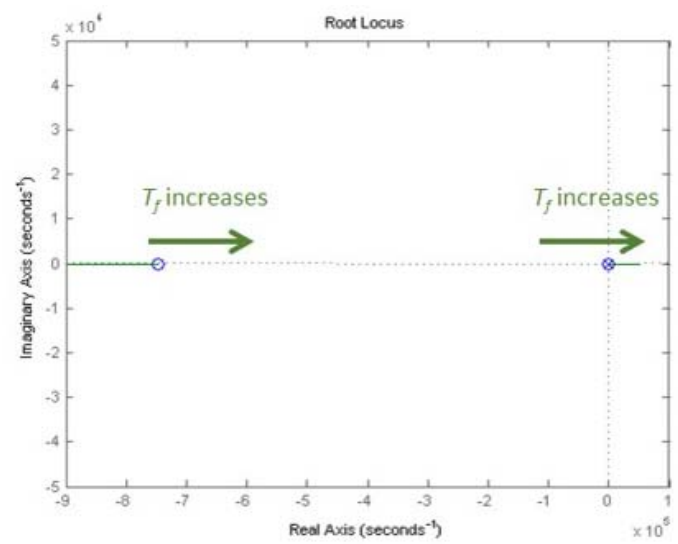

(e)

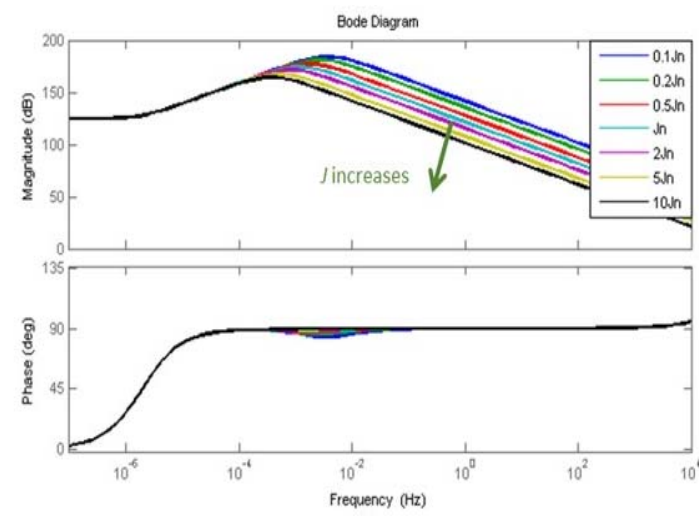

(b)

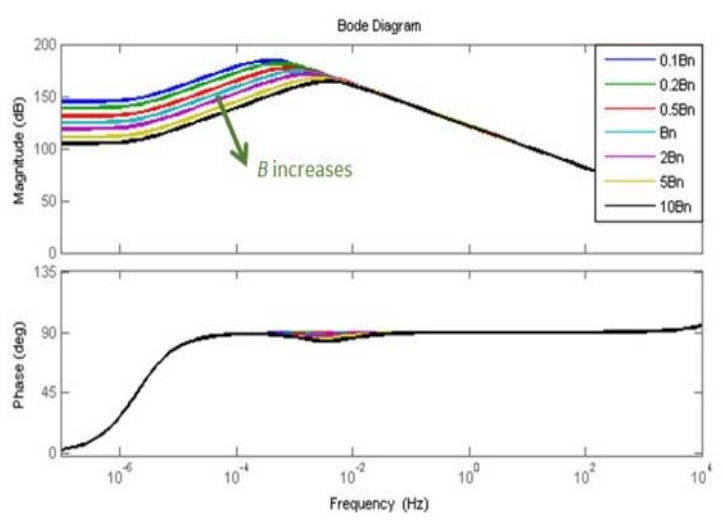

(d)

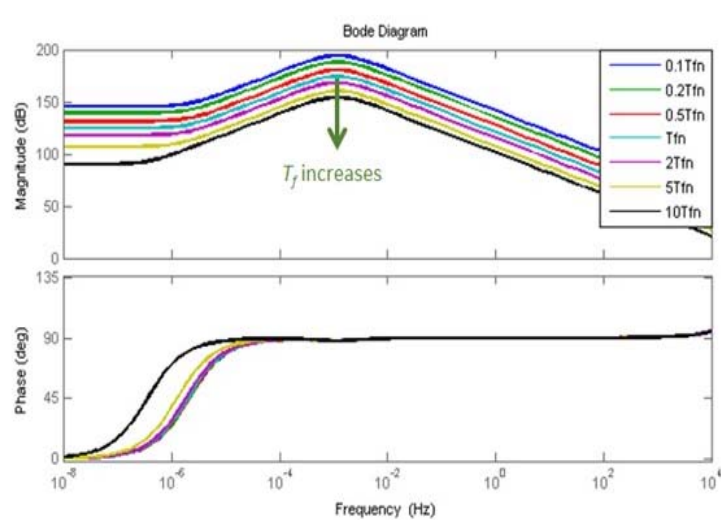

(f)

Figure 6. (a) The effect of changing $J$ (b) Frequency characteristics (change of $J$ ) (c) The effect of changing $B$ (d) Frequency characteristics (change of $B$ ) (e) The effect of changing $T_{f}$ (f) Frequency characteristics (change of $T_{f}$ ) 


\begin{tabular}{|c|c|c|c|}
\hline Parameter & Symbol & Value & Units \\
\hline Nominal Motor inertia & $J_{n}$ & 13.5 & $\mathrm{~g} \mathrm{~cm}^{2}$ \\
\hline Actual Motor inertia & $J$ & 13.5 & $\mathrm{~g} \mathrm{~cm}^{2}$ \\
\hline $\begin{array}{l}\text { Nominal Torque } \\
\text { coefficient }\end{array}$ & $K_{t n}$ & 0.0256 & $\mathrm{Nm} / \mathrm{A}$ \\
\hline $\begin{array}{l}\text { Actual Torque } \\
\text { coefficient }\end{array}$ & $K_{t}$ & 0.0256 & $\mathrm{Nm} / \mathrm{A}$ \\
\hline Proportional constant & $K_{p}$ & 0.001 & - \\
\hline Integral constant & $K_{i}$ & 0.0001 & - \\
\hline Derivative constant & $K_{d}$ & 0.00001 & - \\
\hline $\begin{array}{l}\text { Cut-off frequency of } \\
\text { low pass filter }\end{array}$ & $G_{d i s}$ & $1.00-200.0$ & $\mathrm{~Hz}$ \\
\hline $\begin{array}{l}\text { Viscous friction } \\
\text { coefficient }\end{array}$ & $B$ & 0.0002573 & - \\
\hline Static friction & $T_{f}$ & 0.0375 & $\mathrm{Nm}$ \\
\hline Current feedback gain & $Y$ & 0.01 & $\mathrm{~Hz}$ \\
\hline
\end{tabular}

\subsection{Practical Results}

Initially, in the experiment, one-DOF motion control test was carried out for Figure 7. The external torque was commanded by applying a constant torque input signal as a disturbance signal $T_{\text {dis }}$ for 5 seconds and the module was rotated without the friction compensation. The rotor rotates for 5 seconds and then stops. The velocity response of these rotations, reference torque applied, and disturbance torque as RTOB output is shown in Figure 9 (a), (b) and (c). In ideal systems the RTOB output must be zero if the commanded torque $T_{c m d}$ is zero and in real world systems this can be achieved only with accurate system parameters and friction components. In the proposed system model, the system parameters and friction components were estimated as discussed in previous sections.

For the torque response of the system, it is eveident from Figure 9 (d) that the disturbance torque variation of the system is almost zero when the friction is compensated. This response proves that the proposed method performs competently when the estimated values are close to actual system parameters. Friction compensation was tested with three different motor inertia values, which were calculated in three distinct experiments as estimated in section 3. The authors proposed reverse motion acceleration test is conducted to find the accurate motor inertia. The result of this test is significantly different from the conventional test results. In this paper, friction compensation is represented in the form of a velocity response when a constant external torque is applied to the system externally by applying constant torque input signal as disturbance signal Tdis as shown in Figure 10 (a).

The velocity response graphs for the same external torque with different inertia values are shown in Figure 10 (b)-(d). Three cases were analyzed using the estimated inertia values with respect to estimated frictional values. A velocity response in Figure 10 (d) shows the robust velocity response compared to the previous results in Figure 10 (b) and (c). It is evident from Figure 10 that the friction compensation model showed the outstanding performance when the motor inertia is $19.1 \mathrm{~g} \mathrm{~cm}^{2}$. This value is different from the manufacturer's given value of $13.5 \mathrm{~g} \mathrm{~cm}^{2}$. The manufacturer provided value did not yield the desired system response for the small DC motor used in this research. These tests were carried out assuming the system is linear. For the next phase, authors will extend this research towards MU-LapaRobot (Minimally Invasive Surgical Robot) robust control [51]. The system response can be further improved by introducing nonlinear control techniques, especially adaptive fuzzy hierarchical sliding mode control for a class of MIMO nonlinear time-delay systems with input saturation. 


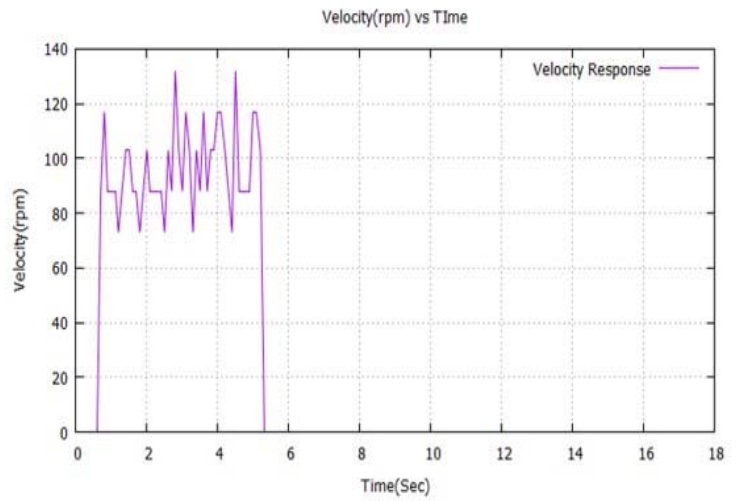

(a)

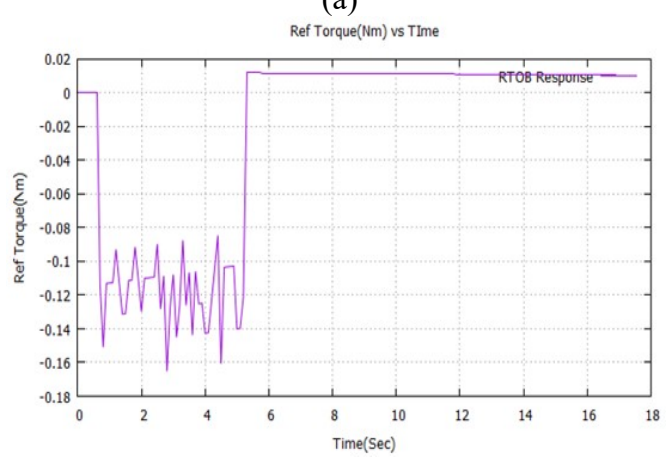

(c)

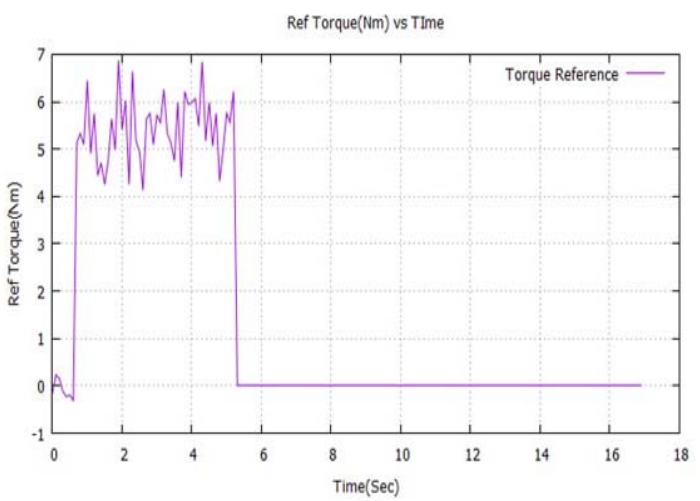

(b)

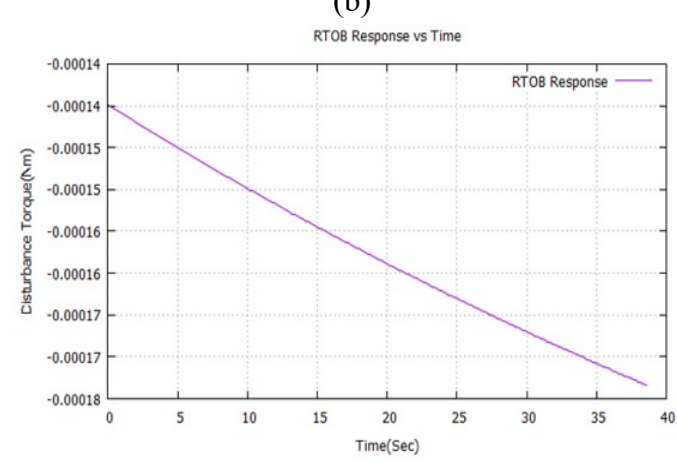

(d)

Figure 7. (a) Velocity response without friction compensation (b) Input torque externally commanded (c) RTOB response without friction compensation (d) RTOB response when friction compensated with estimated value

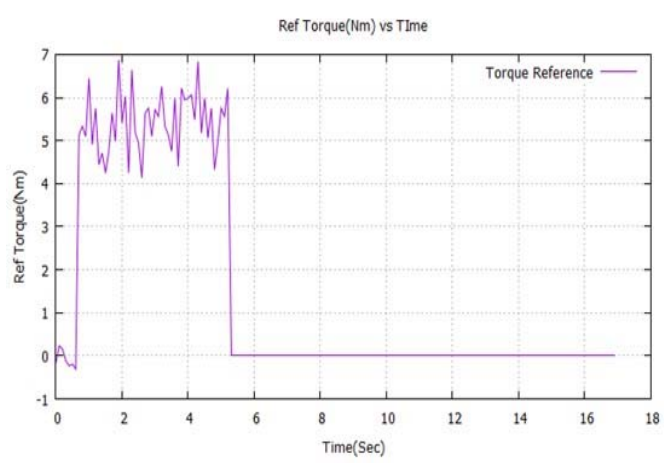

(a)

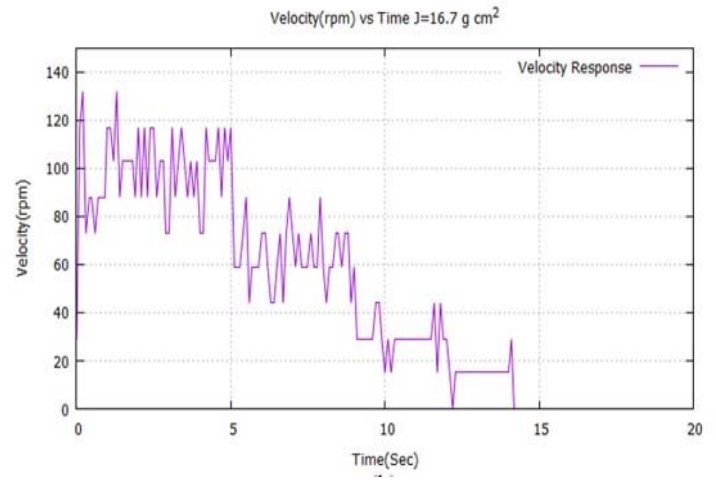

(b) 


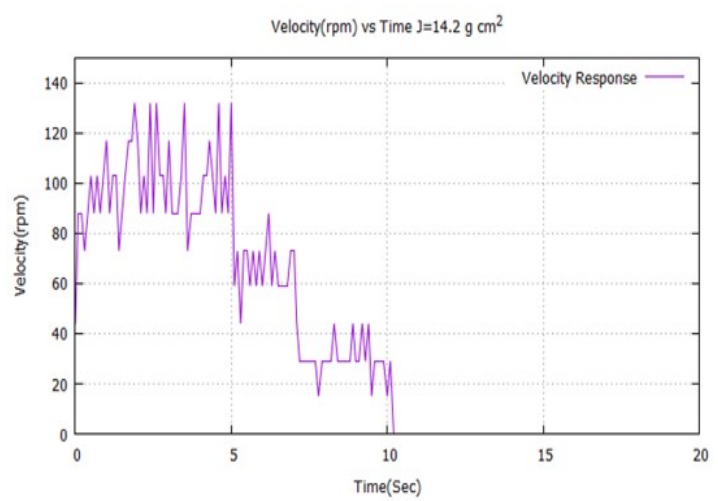

(c)

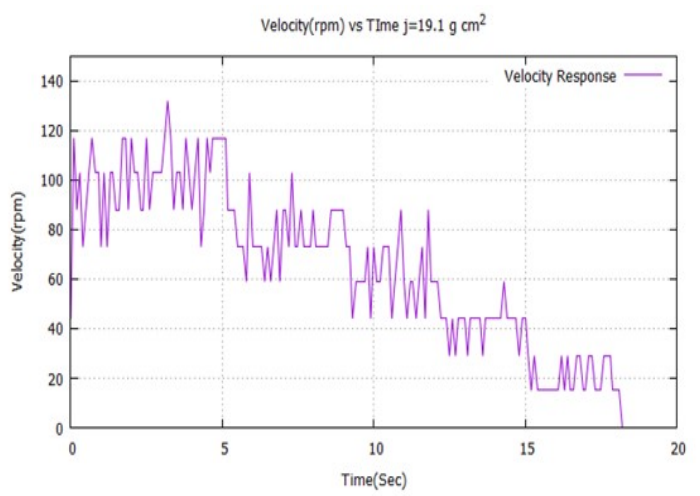

(d)

Figure 8. (a) Input torque externally commanded (b) Velocity response when friction compensated with $\mathrm{J}=16.7 \mathrm{~g} \mathrm{~cm}^{2}$ (c) Velocity response when friction compensated with $\mathrm{J}=14.2 \mathrm{~g} \mathrm{~cm}^{2}$ (d) Velocity response when friction compensated with $\mathrm{J}=19.1 \mathrm{~g} \mathrm{~cm}^{2}$

\section{CONCLUSION}

In this paper, we proposed a novel friction compensation method and motor inertia estimation method to be used specially for small DC motors. Throughout this research, Sensorless torque sensors are used; where DOB is used as the disturbance torque sensor, and RTOB as the external torque sensor. The torque coefficient calculated in the rotor stall test is $0.256 \mathrm{Nm} / \mathrm{A}$. The friction components are estimated by conducting the DOB based constant velocity test. The estimated static friction is $0.0375 \mathrm{Nm}$.and viscous friction coefficient is 0.0002573 . The motor was inertia calculated using three tests; acceleration motion test, deceleration motion test and reverse motion acceleration test. Three different inertia values resulted from these tests and they are separately used for the three friction compensation cases. Friction compensation tests are carried out using the estimated system parameters and these three inertia values are tested with the friction compensator. The proposed method of estimating the motor inertia shows better results. The validity of the proposed friction compensation method and the effect of parameters were verified experimentally.

\section{ACKNOWLEDGEMENTS}

Authors would like to express their gratitude to Health Systems Research Institute of Thailand (HSRI), Grant No. 57-025, Dr.A.M.Harsha S Abeykoon, University of Moratuwa, Sri Lanka for his kind Analytical and Technical support, and also Sakol Nakdhamabhorn, Korn Borvorntanajanya, Chawaphol Direkwatana, Syed Saqib Hussain Shah and BART LAB Researchers for their kind support.

\section{REFERENCES}

[1] K. Ohnishi, M. Shibata, and T. Murakami, "Motion control for advanced mechatronics," IEEE/ASME Trans. Mechatronics, vol. 1 no. 1, pp. 56-67, 1996.

[2] J. Yadav, and J. Suthakorn, "Euclidean Distance and Workspace Region Based Control Algorithm for Collision Avoidance in a Laparoscopic Surgical Robot: MU-LapaRobot," IEEE International Conference on Robotics and Biomimetics (ROBIO), pp. 2056-2061, 2012.

[3] L. Hongbing, K. Kawashima, K. Tadano, S. Ganguly, and S. Nakano, "Achieving Haptic Perception in Forceps' Manipulator Using Pneumatic Artificial Muscle,” IEEE/ASME Trans. Mechatronics, vol. 18, no.1, pp.74-85, 2013.

[4] K. Ohnishi, S. Katsura, and T. Shimono, "Motion Control for Real-World Haptics," IEEE Trans.Ind. Electron. Magazine, vol. 4, no. 2, pp. 16-19, 2010.

[5] C. Lin, H. Yau, and Y. Tian, "Identification and Compensation of Nonlinear Friction Characteristics and Precision Control for a Linear Motor Stage," IEEE/ASME Trans. Mechatronics, vol. 18, no. 4, pp. 1385-1396, 2013.

[6] Y. Maeda, and M. Iwasaki. "Initial Friction Compensation Using Rheology-Based Rolling Friction Model in Fast and Precise Positioning," IEEE Trans. Ind.Electron. vol. 60, no. 9, pp. 3865-3876, 2013.

[7] S. Ahmad, H. Zhang, and G. Liu, "Multiple Working Mode Control of Door-Opening with a Mobile Modular and Reconfigurable Robot,” IEEE/ASME Trans. Mechatronics, vol. 18, no. 3, pp. 833-844, 2013. 
[8] Z. B. Li, Y. J. Lou, Y. S. Zhang, B. Liao, and Z. X. Li, "Type synthesis, kinematic analysis, and optimal design of a novel class of Schonflies- motion parallel manipulators," IEEE Trans. Autom. Sci. Eng., vol. 10, no. 3, pp. 674-686, 2013.

[9] N. Mallon, W. Van-de, D. Putra, and H. Nijmeijer, "Friction compensation in a controlled one-link robot using a reduced-order observer," IEEE Trans. Control Systems Technology, vol. 14, no. 2, pp. 374-383, 2006.

[10] L. Mostefai, M. Denaï, and Y. Hori, "Robust Tracking Controller Design with Uncertain Friction Compensation Based on a Local Modeling Approach," IEEE/ASME Trans. Mechatronics, vol. 15, no. 5, pp. 746-756, 2010.

[11] S. Chalongwongse, and J. Suthakorn. "Workspace Determination and Robot Design of a Prototyped Surgical Robotic System Based on a Cadaveric Study in Endonasal Transsphenoidal Surgery," IEEE International Conference on Robotics and Biomimetics (ROBIO), pp. 241-246, 2014.

[12] Y. Jing, Y. Xian, C. Cailian, L. Xiaoyuan and G. Xinping, "Bilateral Teleoperation of Multiple Agents with Formation Control," IEEE/CAA Journal of Automatica Sinica, vol. 1, no. 2, pp. 141-148, 2014.

[13] N. Tanaiutchawoot, B. Treepong, C. Wiratkapan, and J. Suthakorn, "A Path Generation Algorithm for Biopsy Needle Insertion in a Robotic Breast Biopsy Navigation System," In IEEE International Conference on Robotics and Biomimetics (ROBIO), pp. 398-403, 2014.

[14] M. A. M. Obaid, A. R. Husain, and A. A. M. Al-kubati, "Robust Backstepping Tracking Control of Mobile Robot Based on Nonlinear Disturbance Observer," International Journal of Electrical and Computer Engineering (IJECE), vol. 6, No. 2, pp. 901-908, 2016.

[15] M. Tsai, and C. Huang, "Development of a Variable-Inertia Device with a Magnetic Planetary Gearbox," IEEE/ASME Trans. Mechatronics, vol. 16, no. 6, pp.1120-1128, 2010.

[16] C. Ganesh, B. Abhi, V. P. Anand, S. Aravind, R. Nandhini and S. K. Patnaik, "DC Position Control SystemDetermination of Parameters and Significance on System Dynamics," ACEEE Trans. J. Electrical and Power Eng. Vol. 3, no. 1, pp.1-5, 2012.

[17] D. Sendrescu, "Parameter identification of a DC motor via distribution based approach," IEEE Methods and Models in Automation and Robotics (MMAR), 2012, pp. 17-22.

[18] D. T. Liem, and K. K. Ahn, "DC motor parameters identification and sensorless torque estimation using Fuzzy PID," 12th IEEE Control, Automation and Systems (ICCAS), pp.76-81, 2012.

[19] M. Ruderman, J. Krettek, F. Hoffman, and T. Betran, "Optimal state space control of DC motor," Proceedings of the 17th World Congress IFAC, pp. 5796-5801, 2008.

[20] P. P. Robet, M. Gautier, A. Jubien, and A. Janot, "Global identification of mechanical and electrical parameters of DC motor driven joint with a fast CLOE method," IEEE/ASME Advanced Intelligent Mechatronics (AIM), pp.1205-1210, 2013

[21] S. S. Saab, and R. A. Kaed-Bey, "Parameter identification of a DC motor: an experimental approach," 8th IEEE Electronics, Circuits and Systems (ICECS), pp. 981-984, 2001.

[22] W. Lin, T. Su, R. Wu, and J. Tsai, "Parameter estimation of induction machines under no-load test," IEEE Industrial Electronics and Applications (ICIEA), pp. 1762-1767, 2010.

[23] I. Virgala, P. Frankovsky, and M. Kenderova, "Friction Effect Analysis of a DC Motor," Trans. American Journal of Mech.Eng. vol. 1, no. 1, pp. 1-5, 2013.

[24] H. Kobayashi, S. Katsura, and K. Ohnishi, "An analysis of parameter variations of disturbance observer for haptic motion control,” 31st IEEE Annu.Conf Industrial Electronics Society, IECON, pp. 1907-1912, 2005.

[25] S. Galijasevic, S. Masic, S. Smaka, A. Aksamovic, and D. Balic, "Parameter identification and digital control of speed of a permanent magnet DC motors," 23rd IEEE Information, Communication and Automation Technologies (ICAT), pp. 1-7, 2011.

[26] Y. Mizutani, and S. Katsura, "Micro-macro bilateral control with compensation of gravity and friction," IEEE International Conference on Mechatronics (ICM), pp. 780-785, 2013.

[27] L. Klaus, "Comparison of Two Experiments Based on a Physical and a Torsion Pendulum to Determine the Mass Moment of Inertia Including Measurement Uncertainties," Measurement Science Review, vol. 17, no. 1, pp. 9-18, 2017.

[28] S. A. Ali, M. F. Miskon, A. Z. H. Shukor, and, M. Q. Mhoammed, "The Effect of Parameters Variation on Bilateral Controller," International Journal of Power Electronics and Drive System (IJPEDS), vol. 9, no. 2, pp. 648-659, 2018.

[29] G. Mamani, J. Becedas, H. Sira-Ramirez, and V. Feliu Batlle, "Open-loop algebraic identification method for DC motors," Proceedings of the European Control Conference, pp. 3430-3436, 2007.

[30] G. Mamani, J. Becedas, and V. Feliu-Batlle, "On-line fast algebraic parameter and state estimation for a DC motor applied to adaptive 16 control," Proceedings of the World Congress on Engineering, 2008.

[31] R. Krneta, S. Antic, and D. Stojanovic, "Recursive least square method in parameters identification of DC motors models," Facta Universitatis, vol. 18, no. 3, pp. 467-478, 2005.

[32] M. Hadef and M. R. Mekideche, "Parameter identification of a separately excited DC motor via inverse problem methodology," Proceedings of the Ecologic Vehicles and Renewable Energies, pp. 159-163, 2009.

[33] M. K. C. D. Chinthaka, and A. M. Harsha S. Abeykoon, "Friction Compensation of DC Motors for Precise Motion Control Using Disturbance Observer," ECTI Transactions on Computer and Information Technology, Vol. 9, no. 1, pp 66-74, 2015.

[34] I. Takeuchi, and S. Katsura, "Motion reproduction with time-adaptation control for dealing with variations of environmental location," IEEJ Journal of Industry Applications, Vol. 5, no. 3, pp 221-227, 2016.

[35] M. Eom and D. Chwa, "Robust Swing-Up and Balancing Control Using a Nonlinear Disturbance Observer for the Pendubot System with Dynamic Friction," IEEE Transactions on Robotics, Vol. 31, no. 2, pp331-343, 2015. 
[36] S. A. Ali, M. F. Miskon, A. Z. Hj Shukor, and M. Q. Mohammed, "Single link bilateral haptics control with PD controller and geared DC-motor in robotic rehabilitation technology," Int. J. Mech. Mechatronics Eng., vol. 17, no. 5, pp. 148-155, 2017.

[37] A. M. Abeykoon, and K. Ohnishi, "Virtual tool for bilaterally controlled forceps robot-for minimally invasive surgery," J. Medical Robotics and Computer Assisted Surgery, vol. 3, no. 3, pp. 271-280, 2007.

[38] A. M. Harsha, and K. Ohnishi, "Improvement of Tactile Sensation of a Bilateral Forceps Robot by a Switching Virtual Model," Advanced Robotics, vol. 22, no. 8, pp. 789-806, 2008.

[39] C. Songsong, W. Shengguo, W. Yiheng, L. Qing and W. Yong, "Study on Four Disturbance Observers for FO-LTI Systems," IEEE/CAA Journal of Automatica Sinica, vol. 3, no. (4), pp. 442-450, 2016.

[40] H. Kobayashi, S. Katsura, and K. Ohnishi, "An Analysis of Parameter Variations of Disturbance Observer for Motion Control,” IEEE Trans. Ind.Electron. vol. 54, no. 6, pp. 3413-3421, 2007.

[41] Y. Ohba, M. Sazawa, K. Ohishi, T. Asai, K. Majima, Y. Yoshizawa, and K. Kageyama, "Sensorless Force Control for Injection Molding Machine Using Reaction Torque Observer Considering Torsion Phenomenon," IEEE Trans. Ind. Electron., vol. 56, no. 8, pp. 2955-2960, 2009.

[42] E. Saito, and S. Katsura, "A filter design method in disturbance observer for improvement of robustness against disturbance in time delay system," IEEE Industrial Electronics (ISIE), pp. 1650-1655, 2012.

[43] S. Funabiki, and T. Fukushima, "Current commands for high-efficiency torque control of DC shunt motor," IEE Proceedings B - Electric Power Applications, vol. 138, no. 5, pp. 227-332, 1991.

[44] A. M. H. S. Abeykoon, and H. R. Senevirathne, "Disturbance observer based current controller for a brushed DC motor," 6th IEEE Information and Automation for Sustainability (ICIAfS), pp. 47-52, 2012.

[45] S. Behbahani, and C.W. de Silva, "Niching Genetic Scheme with Bond Graphs for Topology and Parameter Optimization of a Mechatronic System," IEEE/ASME Trans. Mechatronics, vol. 19, no. 1, pp. 269-277, 2014.

[46] N. S. Hasan, N. Rosmin, S. A. Khalid, D. A. A. Osman, B. Ishak and A.H. Mustaamal, "Harmonic Suppression of Shunt Hybrid Filter using LQR-PSO based," International Journal of Electrical and Computer Engineering, (IJECE), Vol. 7, no. 2, pp. 869-876, 2017.

[47] R. Minaki, H. Hoshino, and Y. Hori, "Driver steering sensitivity design using road reaction torque observer and viscous friction compensation to Active front steering," IEEE Industrial Electronics (ISIE), pp. 155-160, 2010.

[48] K. Ito, M. Iwasaki, and N. Matsui, "GA-based practical compensator design for a motion control system," IEEE/ASME Trans. Mechatronics, vol. 6, no. 2, pp. 143-148, 2001.

[49] M. Kušnerová, J. Valíček, M. Harničárová, T. Hryniewicz, K. Rokosz, Z. Palková, V. Václavík, M. Řepka, and M. Bendová, "A Proposal for Simplifying the Method of Evaluation of Uncertainties in Measurement Results," Measurement Science Review, vol. 13, no. 1, pp. 1-6, 2013.

[50] Xingjian Wang, Shaoping Wang, and Bin Yao, "Adaptive robust torque control of electric load simulator with strong position coupling disturbance," International Journal of Control, Automation and Systems, vol. 11, no. 2, pp. 325-332, 2013.

[51] C. Direkwatana, and J. Suthakorn, "Development of Wire-Driven Laparoscopic Surgical Robotic System, MULapaRobot," IEEE International Conference on Robotics and Biomimetics (ROBIO), pp. 485-490, 2011.

Int J Pow Elec \& Dri Syst, Vol. 10, No. 1, March 2019: $195-210$ 